doi: $10.1017 / S 1092852912000120$

\title{
The Mental Status Exam in Talmudic Medicine
}

Stephen I. Deutsch, MD, PhD

Return

Dr. Deutsch is Ann Robinson Endowed Chair in Psychiatry and professor and chairman of the Department of Psychiatry and Behavioral Sciences at Eastern Virginia Medical School in Norfolk.

Faculty Disclosures: The author reports no affiliation with or financial interest in any organization that might pose a conflict of interest.

Submitted for publication: October 7, 2009; Accepted for publication: February 23, 2010; First published online: January 1, 2011.

Please direct all correspondence to: Stephen I. Deutsch, MD, PhD, Eastern Virginia Medical School, Department of Psychiatry and Behavioral Sciences, 825 Fairfax Ave, Se 710, Norfolk, VA 23507; Tel: 757-446-5888, Fax: 757-446-5918; E-mail: deutscsi@EVMS.EDU.

To the Editor:

An early reference to the clinical evaluation of "delirium" appears in the seventh chapter of the Talmudic tractate dealing with divorce documents and proceedings. 1 The Rabbis in Mishnaic (ie, Tannaim) and Talmudic (ie, Amoraim) times, extending from the beginning of the Common Era to $~ 800 \mathrm{CE}$, needed absolute assurance regarding a husband's willful intention to divorce his wife for a variety of religious, legal and social reasons. These reasons include, but are not limited to: the fact that once properly divorced a member of the Priestly sect cannot remarry his divorced wife, and religiously-valid divorces are necessary to assure that biological offspring of a remarried, but improperly-divorced, wife are not religiously and socially ostracized; these "illegitimate" offspring are referred to as Mamzerim. In addition, in the event a couple was childless, there were circumstances where a devoted husband would proactively give his wife a "conditional" divorce that would go into effect "retroactively" if he were to be confirmed dead as a result of a dangerous journey, war, or terminal illness; this was done in order to free her of the biblical obligation of Levirate marriage. A valid divorce document was essential to the woman's ability to petition religious courts successfully in order to collect the monetary support outlined in her original marriage document. The religious importance of assuring valid divorce and its documentation was also reflected in the necessity of messengers carrying these documents on behalf of a husband residing outside of Israel to his wife residing within Israel to take oaths that the writing and signing of the divorce document were 
witnessed, and it was prepared specifically for the wife with the husband's full intention. Of necessity, the document contains all of the possible names by which the to-be-divorced parties could be referred in different languages and geographic locations.

The Rabbis performed an abbreviated "bedside" examination of the mental state when a husband presented with alternating levels of alertness, awareness, and consciousness or mutism. Importantly, temporal course was also considered; clearly, expression of intent to divorce that preceded an altered cognitive state had different religious and legal implications than similar expressions made at other times. The Rabbis understood that resolution of delirium, dementia, and delirium superimposed on dementia required integration of longitudinal history with cross-sectionally administered index and follow-up examinations. The assessment included elicitation of consistent yes or no responses over intervals and the naming of items and fruits appropriate to a particular season. For example, one suspected of delirium or altered competence could be asked whether he desired items (eg, articles of clothing) in winter that were suitable for the summer months; the selection of unsuitable items was consistent with diminished mental capacity. The text provides specific instructions for asking six questions unrelated to the divorce document that require signaling the following sequence of correct answers: "no, yes, yes, no, no, and yes." The exclusion of response bias to categorical questions requiring "yes/no" responses or correct responses due to chance was accomplished by asking these specific questions, whose correct pattern of responding could not be mimicked by chance and would detect biased responding. This was especially important in the context of mutism that necessitated head nodding as the mode of responding. Rashi, an authoritative medieval commentator, explains that a confused mental state would be unlikely to result in this correct pattern of responding.

The Rabbis relied on history and clinical skill to assure that the husband met the standard of a religiously acceptable divorce with all of its legal and social implications.

Sincerely, Stephen I. Deutsch, MD, PhD

\section{Reference}

1. ?Gittin. In: The Babylonian Talmud. Classic Vilna Edition: 67b, 70b. 